\title{
Anticarcinogenic potential of ethanol extract of Indigofera cordifolia Roth. (Fabales: Fabaceae) on diethylnitrosamine induced hepatocarcinogenesis in rats
}

\section{Raju Senthil Kumar ${ }^{1 * *}$, Gopal Murugananthan ${ }^{1}$ and Balasubramanian Rajkapoor $^{2}$}

${ }^{1}$ Natural Products Laboratory. Swamy Vivekanandha College of Pharmacy. Tiruchengode. Tamilnadu. India.*Email: thrisen@gmail.com.

2Department of Pharmacology. Faculty of Medicine. Sebha University. Sebha. Libya.

\begin{abstract}
Indigofera cordifolia Roth. (Fabales: Fabaceae) has been widely used in Indian system of medicine to treat various disorders. Earlier studies showed that I. cordifolia (EIC) possess antioxidant, free radical scavenging and antitumour activities. The present investigation was designed to evaluate the anticarcinogenic potential of EIC against diethylnitrosamine (DEN) induced hepatocellular carcinoma in male Wistar rats. Hepatocarcinogenesis was induced by a single intraperitoneal administration of DEN $(200 \mathrm{mg} / \mathrm{kg})$ and the carcinogenic effect was promoted by phenobarbital given through drinking water for 16 successive weeks. EIC at the dose of 200 and $400 \mathrm{mg} / \mathrm{kg} /$ day were administered orally for the entire study period. After the end of experimental period, changes in body weight, the weight of liver, relative liver weight, lipid peroxidation, antioxidant, serum hepatic parameters, tumour markers, DNA, RNA and protein content were analysed. Treatment with EIC significantly increased the body weight $(\mathrm{P}<0.01-0.001)$, reduced the liver weight and relative liver weight $(\mathrm{P}<0.01-0.001)$, restored the altered serum hepatic parameters $(\mathrm{P}<0.001)$, down-regulated the serum tumour markers such as alpha-fetoprotein and carcinoembryonic antigen $(\mathrm{P}<0.001)$ when compared to DEN group. EIC treatment restored the antioxidant enzymes and significantly reduced the lipid peroxidation in DEN-treated animals $(\mathrm{P}<0.001)$. EIC treatment also significantly reduced the elevated levels of nucleic acid levels and restored the protein content in liver tissues $(\mathrm{P}<0.001)$. We investigated the anticarcinogenic potential of EIC against DENinduced HCC in rats. Chemoprotective effect of the extract might be related with antioxidant, free radical scavenging and reduction of lipid peroxidation. The results suggested that EIC would be a potent anticarcinogenic agent inhibiting DEN-induced hepatic carcinoma.
\end{abstract}

Keywords: Indigofera cordifolia; Diethylnitrosamine; Serum hepatic parameters; Carcinoembryonic antigen; Alpha-fetoprotein; Chemoprevention.

\section{Introduction}

Cancer is a worldwide challenge and remains the largest reason of death
Received

May 17, 2017

Accepted

June 24, 2017

Released

June 30, 2017

Open Acess

Full Text Article

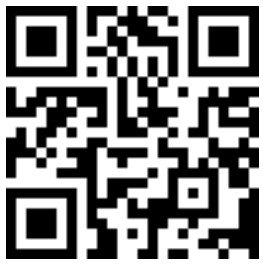

ORCID

다 0000-0003-1309-3886

Raju Senthil Kumar

(D) 0000-0001-6472-9173

Gopal Murugananthan

(D) 0000-0002-1125-7800

Balasubramanian

Rajkapoor around the globe. Increase in life expectation and adopting western diet and lifestyles, tobacco use and exposure to carcinogens are the principal factors for

Braz. J. Biol. Sci.

http://revista.rebibio.net 
increasing the burden of cancer in the developing countries. Hepatocellular carcinoma (HCC) is the second leading cause of cancer mortality throughout the world (Jemal et al., 2011). It has been joined with totally different etiologies such as chronic hepatitis B and C infection and alcohol use (Shih et al., 2009; Kumar et al., 2011). Because of high tolerance of liver, HCC is never detected at the early phase and treatment includes poor prognosis in most of the cases, creating it a very important health problem (El-Serag and Rudolph, 2007). The relapse rates of HCC are high and also the survival rate of the patient with HCC has not increased in the past few decades. Surgery, including transplantation, is presently the foremost successful treatment for this frightful disease.

The liver is the major organ that involves in the metabolism of many xenobiotics; hence, it is more liable to carcinogenic insult. Diethylnitrosamine (DEN) is a potent environment carcinogen that is entered through the food chain. DEN is synthesised endogenously and located in occupational settings, tobacco smoke, processed meat, alcoholic beverages, agricultural chemicals, cosmetics and pharmaceutical substances. It is made from metabolism of certain medication. It causes proliferative, chronic and cancerous lesions in the liver. It will alkylate DNA with itself being converted to the extremely reactive molecule by CYP450 dependent oxygenases and generates reactive oxygen species (ROS) inflicting oxidative stress. It also induces chromosomal aberrations, micronuclei and chromatid exchanges in the liver and these mutations evoked by DEN are responsible for the event of carcinoma (Sivaramakrishnan et al., 2008; Mandal et al., 2008; Jagadeesh et al., 2009). The rat model of DEN-induced carcinoma is the foremost accepted and widely used experimental model to study the chemopreventive and chemotherapeutic potential of many drugs. Human liver metabolises DEN similar to that of rat liver with relevance such as genetic alteration, morphology and gene expression. Considering the narrow treatment options and prognosis of HCC, chemoprevention has considered being the best approach in lowering the morbidity and death associated with this disease. Chemoprevention is the modern strategy to manage primary liver cancer. It is the mode of cancer management during which the prevalence of the disease are often prevented, delayed or reversed by the administration of one or more natural and/or synthetic agent. Epidemiologic evidence have exposed the chemopreventive effect of the many medicinal plants and their phytochemicals in the prevention of the disease.

$$
\text { Indigofera cordifolia Roth. }
$$

(Fabales: Fabaceae) it is an Indian medicinal plant and has long been used by ethnic people and native medical practitioners to treat diseases like rheumatism, arthritis, inflammation, neoplasm and liver diseases. Literature survey revealed that crude methanol and aqueous extracts of seeds of this plant has potent antioxidant, radical scavenging and wound healing activities (Tambe et al., 2010; Sarin and Upman, 2011; Khatri et al., 2013). Earlier studies on this plant in our laboratory revealed that the ethanol extract of entire plant possesses potent antioxidant, radical scavenging and antineoplastic properties in transplantable tumour models (Thangavel et al., 2014; Thangavel et al., 2015). Based on the results obtained from our previous works, an attempt was made to check the anticarcinogenic impact of ethanol extract of I. cordifolia (EIC) against DEN-induced phenobarbitone promoted hepatocarcinogenesis in rat model.

\section{Materials and methods}

\section{Chemicals}

Diethylnitrosamine (DEN) and phenobarbitone were purchased from Sigma Chemicals Co. (St. Louis, MO, USA). Carboxy methyl cellulose (CMC) was procured from Loba Chemie (Mumbai, India). All other chemicals used for the experiments were of analytical grade.

Animals

Male Wistar rats (150-160 g) were purchased from Venkateshwara Enterprises, 
Bangalore, India. They were maintained in standard microlon boxes and were given standard laboratory diet and water ad libitum. The study was conducted after obtaining Institutional Animal Ethical Committee (IAEC) clearance and the animals were handled as per the Committee for the Purpose of Control and Supervision of Experiments on Animals (CPCSEA) guidelines of Good Laboratory Practice.

\section{Plant material and extraction}

The whole plant of I. cordifolia was collected from Tiruchengode, Namakkal District, Tamilnadu, in the month of November 2015. The plant was then authenticated by a botanist from Botanical Survey of India, Coimbatore and a voucher specimen is preserved in our laboratory for further reference (Voucher specimen No. P. Chem/SVCP/15-16/IC-0213). The shade dried, powdered plant material was extracted with $80 \% \quad \mathrm{v} / \mathrm{v}$ ethanol by continuous hot percolation process using soxhlet apparatus for $72 \mathrm{~h}$. The extract was filtered and concentrated to dryness under reduced pressure and controlled temperature $\left(50^{\circ} \mathrm{C}-60{ }^{\circ} \mathrm{C}\right)$ in a rotary evaporator. A brownish yellow solid mass obtained was stored in a vacuum desiccator until further use.

\section{Experimental design}

The rats were divided into four groups, each group consisting of twelve animals. The liver tumour was induced in groups II-IV with a single intraperitoneal injection of diethylnitrosamine (DEN) at a dose of $200 \mathrm{mg} / \mathrm{kg}$ body weight in saline. Two weeks after DEN administration, the carcinogenic effect was promoted by $0.05 \%$ phenobarbital (PB) that was supplemented to the experimental animals through drinking water for up to 16 consecutive weeks (Rajkapoor et al., 2005). Group I animals served as normal control that received $1 \mathrm{~mL} / \mathrm{kg}$ body weight of $0.3 \%$ carboxymethyl cellulose (CMC) through the oral route. Group II animals served as DEN+ PB control animals and treated same as group I animals. Based on our previous studies, Group III and IV animals were treated with EIC at the dose of 200 and
$400 \mathrm{mg} / \mathrm{kg}$ body weight (Thangavel et al., 2015), by oral route for sixteen consecutive weeks on five days per week. At the end of experiments, blood was collected from overnight fasted animals by retro-orbital plexus method after anaesthetized slightly with anaesthetic ether and serum was separated out. The animals were sacrificed and the liver was immediately removed, washed with ice-cold saline and subsequently blotted with filter paper, then weighed. A small portion of liver was fixed in $10 \%$ formalin solution for histopathological studies.

\section{Serum biochemical and tumour markers estimation}

Serum was analysed for aspartate aminotransferase (AST), alanine aminotransferase (ALT), alkaline phosphatase (ALP), gamma glutamate transpeptidase (GGTP), total cholesterol and total bilirubin by using commercial kits (Agappe diagnostics and Ecoline Diagnostic Kits, India) following the manufacturer's instruction. Liver tumour markers like Alpha-fetoprotein (AFP) and Carcinoembryonic antigen (CEA) in rat serum were estimated by using commercially available ELISA kits (USCN life science Inc. Wuhan, China) according to the manufacturer's instruction. A $10 \%$ liver homogenate of liver tissue was prepared in cold phosphate buffer $(0.05 \mathrm{M}$, $\mathrm{pH} 7.4$ ) and it was centrifuged at 10,000 rpm for $15 \mathrm{~min}$ at $4{ }^{\circ} \mathrm{C}$ to get a clear supernatant. Then it was used for analysis of lipid peroxidation (LPO) (Devasagayam and Tarachand, 1987), catalase (CAT) (Sinha, 1972), superoxide dismutase (SOD) (Marklund and Marklund, 1974), glutathione peroxidase (GPx) (Rotruck et al., 1973) and glutathione S-transferase (GST) (Habig et al., 1974). The liver homogenate was additionally used for the estimation of DNA, RNA and protein content in liver tissues (Schinder, 1957; Burton, 1956; Lowry et al., 1951).

\section{Histopathological examination}

The portion of the liver previously fixed in formalin was embedded in paraffin, 
sectioned at $5 \mu \mathrm{m}$ and stained with haemotoxylin-eosin. Light microscopy was used to evaluate pathological changes of the liver.

\section{Statistical analysis}

The values were expressed as mean \pm SEM. Statistical analysis was performed by one-way analysis of variance (ANOVA) followed by Tukey multiple comparison test using InStat Prism version 4.0. $P$ value $<0.05$ was considered as significant.

\section{Results}

Effect of EIC on body weight

Anticarcinogenic potential of EIC was assessed by finding out the body weight changes in liver neoplasm bearing rats. The results revealed that the body weights were significantly diminished in DEN + PB treated group $(\mathrm{P}<0.001)$. The animals treated with plant extract at the dose of $200 \mathrm{mg} / \mathrm{kg}$ showed a moderately significant increment in body weight in comparison to the DEN $+\mathrm{PB}$ group $(\mathrm{P}<0.01)$. At the same time, the group treated with $400 \mathrm{mg} / \mathrm{kg}$ showed a significant increase in the body weight when compared to tumour control group $(\mathrm{P}<0.001)$. However, no significant difference was ascertained between the tested dose levels. The gain in body weight and protection from weight loss by the extract treatment indicates the nourishing and chemoprotective properties of the extract. The body weight changes are given in Figure 1.

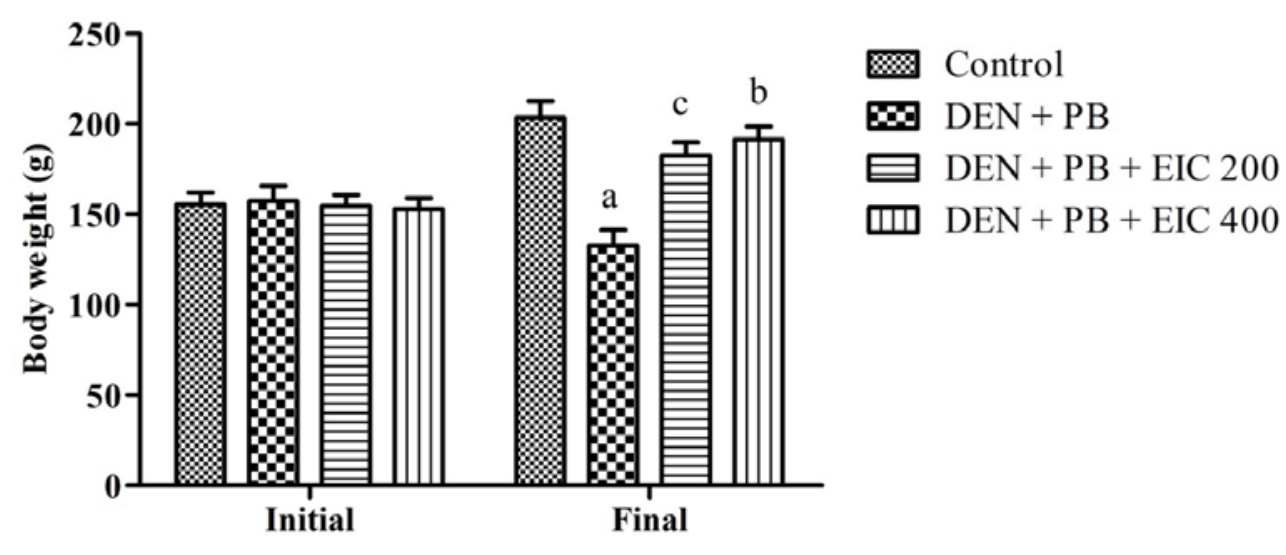

Figure 1. Effect of EIC on body weight changes in liver tumour bearing animals. Number of animals used per group $=12$. Values are expressed as Mean \pm SEM. ${ }^{\mathrm{a}} \mathrm{P}<0.001$ vs Control; ${ }^{\mathrm{b}} \mathrm{P}<0.001,{ }^{\mathrm{c}} \mathrm{P}<0.01$ vs DEN + PB. Data were analysed by one-way ANOVA followed by Tukey-Kramer Multiple Comparison Test.

\section{Effect of EIC on liver weight and relative liver weight}

Figure 2 illustrates liver weight and relative liver weight changes from the normal, DEN + PB as well as extract treated animals. A significant increase in liver weight and relative liver weight was ascertained in DEN + PB alone treated animals $(\mathrm{P}<0.001)$ when compared to normal control. The extract treatment considerably ( $\mathrm{P}<0.001$ to $\mathrm{P}<0.05$ ) inhibit the gain in the liver weight and relative liver weight. No significant weight difference was observed between the tested dose levels. 


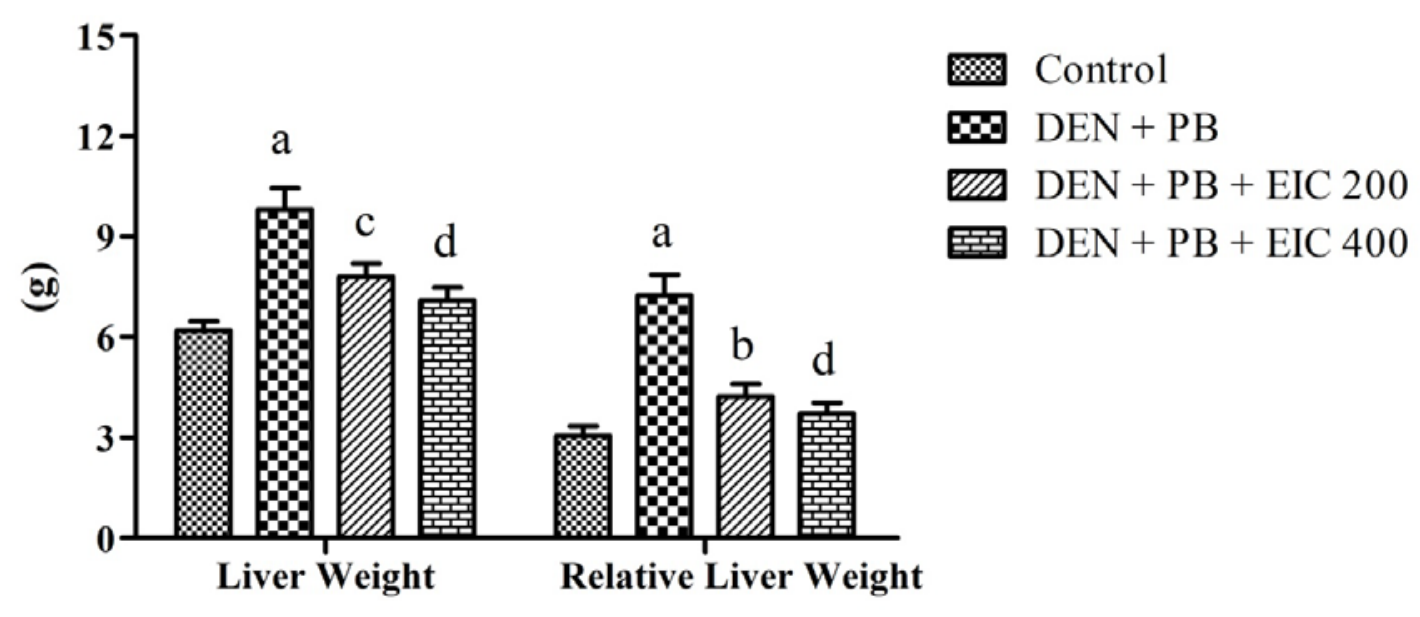

Figure 2. Effect of EIC on liver weight and relative liver weight of different groups. Number of animals used per group $=12$. Values are expressed as Mean \pm SEM. ${ }^{\mathrm{a}} \mathrm{P}<0.001$ vs Control; ${ }^{\mathrm{b}} \mathrm{P}<0.001$, ${ }^{\mathrm{C}} \mathrm{P}<0.01$, ${ }^{\mathrm{d}} \mathrm{P}<0.05$ vs DEN + PB. Data were analysed by one-way ANOVA followed by Tukey-Kramer Multiple Comparison Test.

\section{Effect of EIC on serum hepatic parameters \\ From Figure 3, it is clearly evident} that DEN + PB treatment caused significant elevation of liver serum markers. In the $\mathrm{DEN}+\mathrm{PB}$ treated group, the level of ALT, AST, ALP, GGTP, total cholesterol and total bilirubin were considerably elevated $(\mathrm{P}<0.001)$. In contrast, the groups treated with EIC at the tested dose levels, was able to reverse all the elevated serum hepatic parameters to close normal $(\mathrm{P}<0.001$ to 0.05). The results indicate that the extract potentially defends the liver cells from carcinogenic insult.

\section{peroxidation}

Effect of EIC on lipid

The level of lipid peroxidation was estimated from the liver homogenate of experimental animals. Administration of $\mathrm{DEN}+\mathrm{PB}$ led to a significant increase $(\mathrm{P}<0.001)$ in the level of lipid peroxidation. Treatment of rats with EIC at a dose of 200 and $400 \mathrm{mg} / \mathrm{kg}$ markedly prevented the DEN + PB elicited alterations of lipid peroxidation. Figure 4 illustrated the impact of EIC on lipid peroxidation levels of different treatment groups.

\section{Effect of EIC on antioxidant enzyme levels \\ $\mathrm{DEN}+\mathrm{PB}$ treatment in rats} significantly attenuated the antioxidant defence enzyme levels in the liver homogenate $(\mathrm{P}<0.001)$. Treatment with EIC at the tested dose levels significantly elevated the antioxidant enzymes like catalase, superoxide dismutase, glutathione peroxidase and glutathione S-transferase levels in the liver tumour induced rats. The levels of antioxidant enzymes are displayed in Figure 5.

\section{Effect of EIC on serum tumour markers}

Effect of EIC on serum liver tumour specific markers such as alphafetoprotein (AFP) and carcinoembryonic antigen (CEA) are presented in Figure 6. $\mathrm{DEN}+\mathrm{PB}$ treatment significantly elevated the levels of AFP and CEA $(\mathrm{P}<0.001)$, whereas, the treatment with EIC significantly reduced the raised levels of these serum specific tumour markers. 
A)



C)

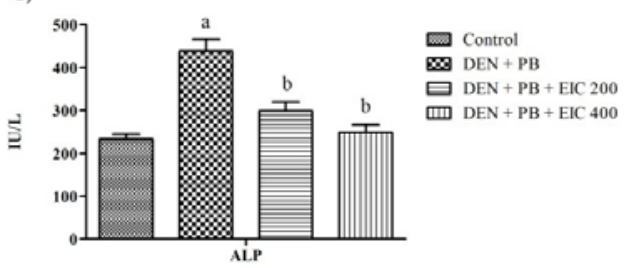

E)

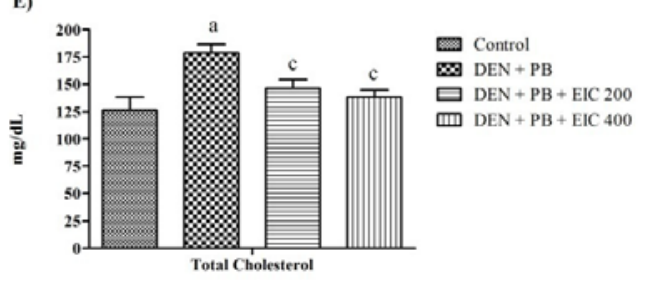

B)

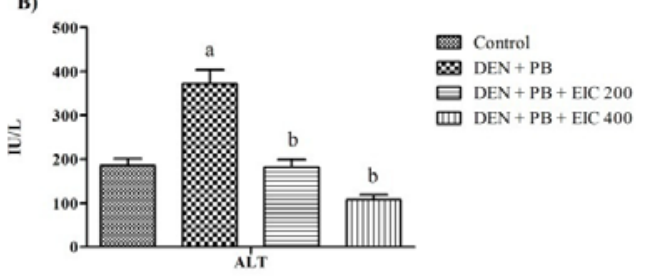

D)

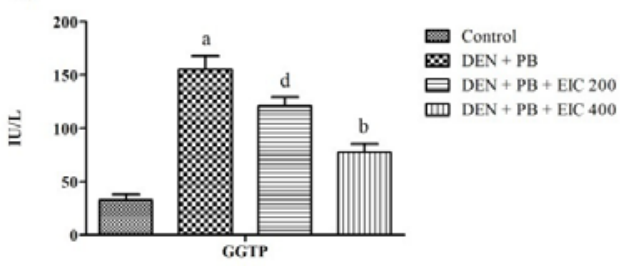

F)

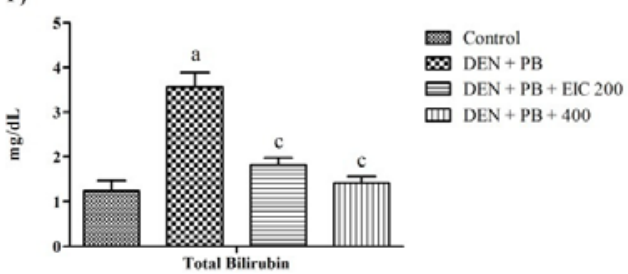

Figure 3. Effect of EIC on serum hepatic parameters of different treatment groups. Number of animals used per group $=12$. Values are expressed as Mean \pm SEM. ${ }^{a} \mathrm{P}<0.001$ vs Control; ${ }^{b} \mathrm{P}<0.001,{ }^{\mathrm{c}} \mathrm{P}<0.01$, ${ }^{\mathrm{d}} \mathrm{P}<0.05$ vs DEN + PB. Data were analysed by one-way ANOVA followed by Tukey-Kramer Multiple Comparison Test.

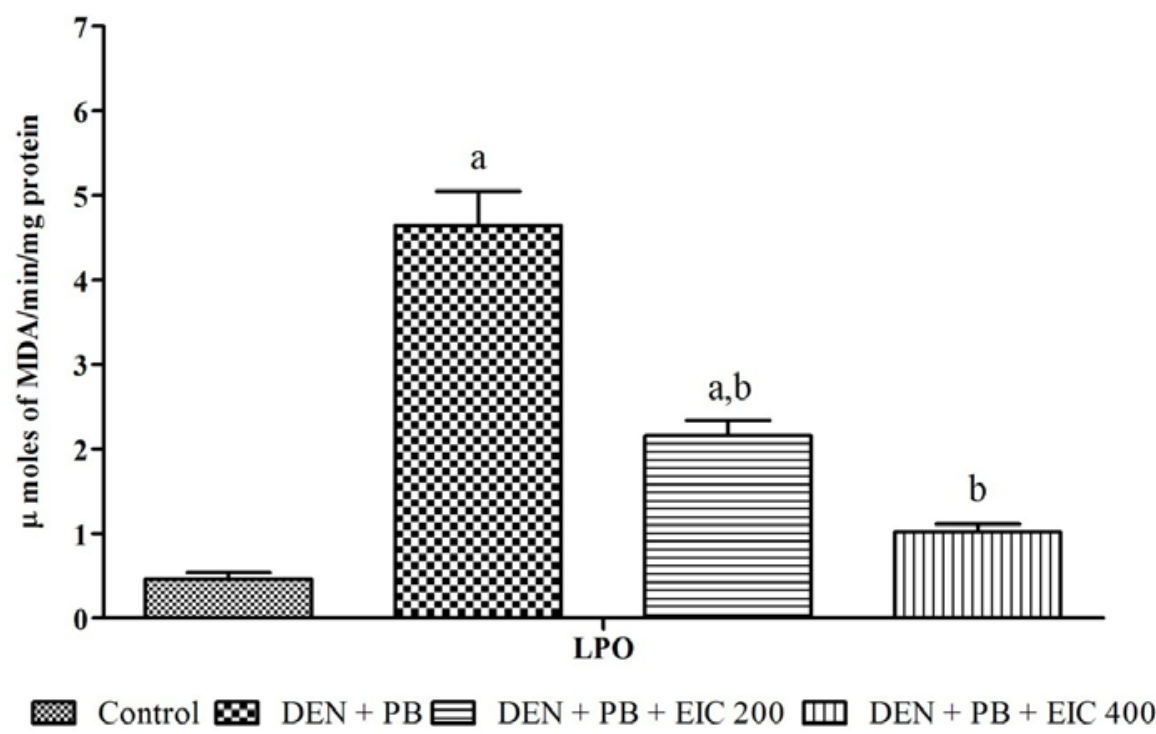

Figure 4. Effect of EIC on lipid peroxidation levels of different treatment groups. Number of animals used per group $=12$. Values are expressed as Mean \pm SEM. ${ }^{\mathrm{a}} \mathrm{P}<0.001$ vs Control; ${ }^{\mathrm{b}} \mathrm{P}<0.001$ vs DEN + PB. Data were analysed by one-way ANOVA followed by Tukey-Kramer Multiple Comparison Test. 
A)

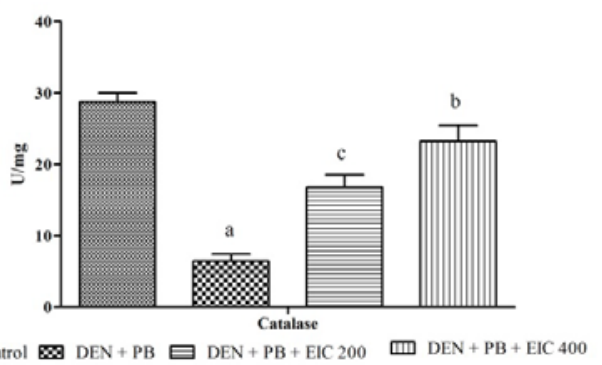

C)

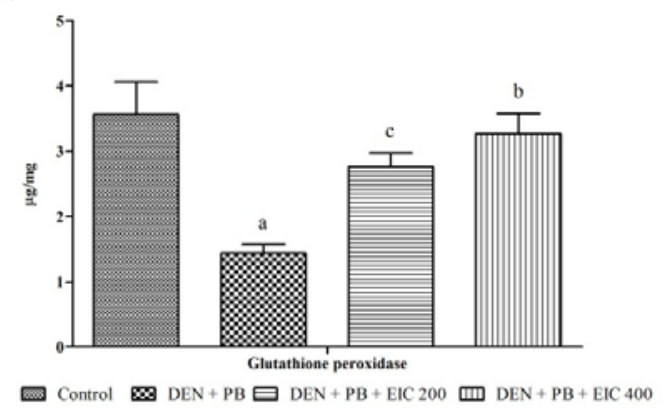

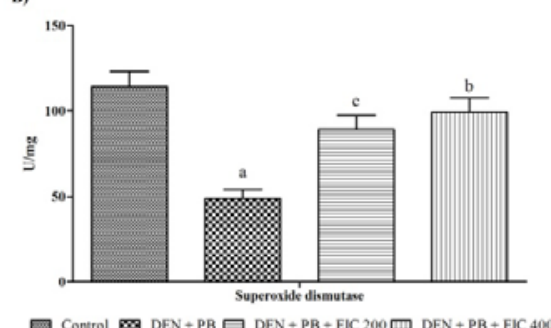

D)

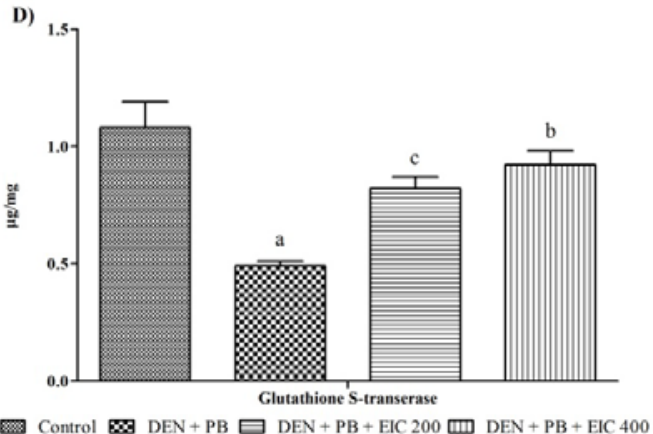

Figure 5. Effect of EIC on antioxidant enzyme levels of different treatment groups. Number of animals used per group $=12$. Values are expressed as Mean \pm SEM. ${ }^{a} \mathrm{P}<0.001$ vs Control; ${ }^{b} \mathrm{P}<0.001,{ }^{c} \mathrm{P}<0.01$ vs DEN + PB. Data were analysed by one-way ANOVA followed by Tukey-Kramer Multiple Comparison Test. SOD, units $/ \mathrm{min} / \mathrm{mg}$ protein; CAT, $\mu$ mole of $\mathrm{H}_{2} \mathrm{O}_{2}$ consumed $/ \mathrm{min} / \mathrm{mg}$ protein; GPx, $\mu$ moles of GSH oxidized/min/mg protein; GST, $\mu$ moles of CDNB conjugation formed $/ \mathrm{min} / \mathrm{mg}$ protein.

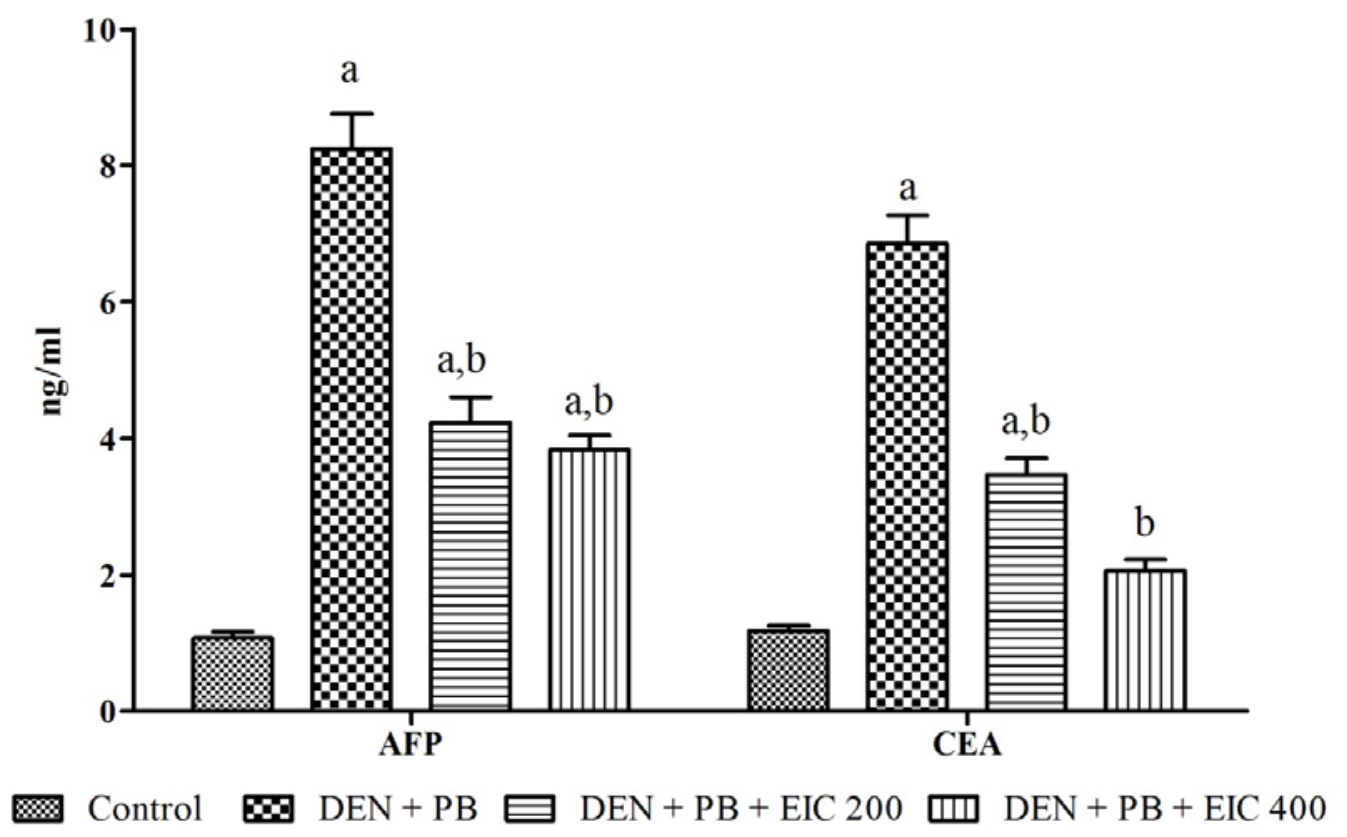

Figure 6. Effect of EIC on serum tumour markers of different treatment groups. Number of animals used per group $=12$. Values are expressed as Mean \pm SEM. ${ }^{a} \mathrm{P}<0.001$ vs Control; ${ }^{b} \mathrm{P}<0.001$ vs DEN $+\mathrm{PB}$. Data were analysed by one-way ANOVA followed by Tukey-Kramer Multiple Comparison Test. 


\section{Effect of EIC on DNA, RNA and protein content}

It is clearly evident from the Figure

7 that DEN + PB caused significant elevation of DNA and RNA and decreases in liver tissue protein levels $(\mathrm{P}<0.001$ to
0.01). In contrast, the groups treated with EIC at the dose of 200 and $400 \mathrm{mg} / \mathrm{kg}$ decreased the elevated levels of DNA and RNA and increase the protein level towards normalisation $(\mathrm{P}<0.01$ and $\mathrm{P}<0.05)$.

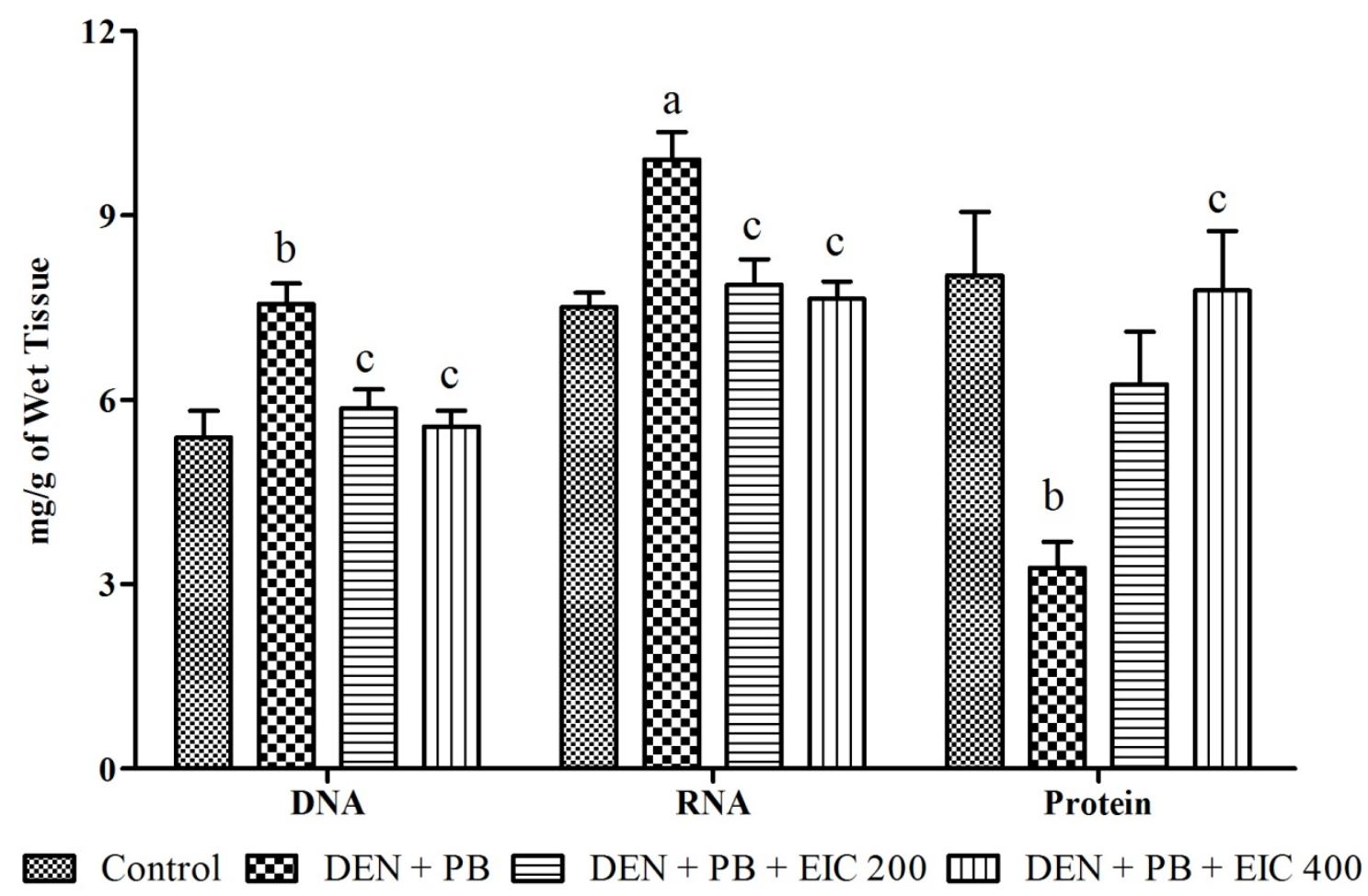

Figure 7. Effect of EIC on DNA, RNA and protein content of different treatment groups. Number of animals used per group $=12$. Values are expressed as Mean \pm SEM. ${ }^{\mathrm{a}} \mathrm{P}<0.001,{ }^{\mathrm{b}} \mathrm{P}<0.01$ vs Control; ${ }^{c} \mathrm{P}<0.01$ vs DEN + PB. Data were analysed by one-way ANOVA followed by Tukey-Kramer Multiple Comparison Test.

\section{Histopathological study}

The histopathological examinations support the results obtained from serum hepatic enzymes and serum liver tumour specific markers. Figure 8A revealed the normal architecture (Control) and hepatic cells with granulated cytoplasm, small uniform nucleus and nucleolus. The animals treated with DEN + PB showed loss of architecture and cancerous cells arranged in lobules with the inflammatory collection and small bile duct proliferation
(Figure 8B). The architecture of liver sections co-administered with EIC 200 $\mathrm{mg} / \mathrm{kg}$ showed normal architecture with some liver cells and minimum inflammatory cell infiltration around portal triads with few neoplastic hepatocytes (Figure 8C). The rats treated with EIC 400 $\mathrm{mg} / \mathrm{kg}$ showed normal architecture with very few pre-neoplastically transformed cells and hepatocytes maintaining normal architecture which was almost comparable to the control group (Figure 8D). 

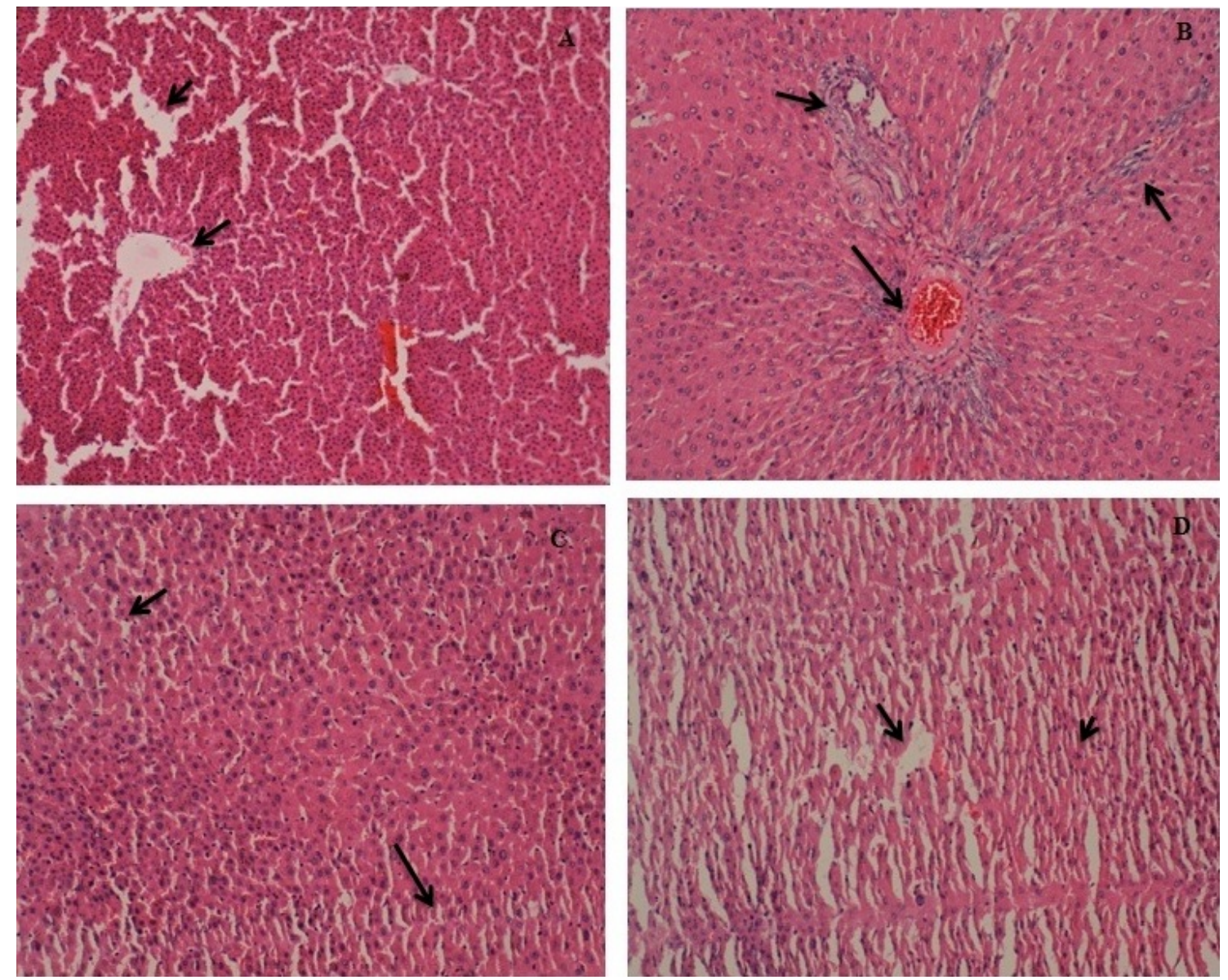

Figure 8. Histopathological study of liver sections of different treatment groups. (A) Control group animals showing normal architecture with granulated cytoplasm, small uniform nucleus and nucleolus. (B) DEN + PB induced hepatocellular carcinoma bearing animals showing loss of architecture and cancerous cells arranged in lobules with the inflammatory collection and small bile duct proliferation. (C) Administration of EIC at the dose of $200 \mathrm{mg} / \mathrm{kg}$ on HCC bearing animals showing normal architecture with some liver cells and minimum inflammatory cell infiltration around portal triads with few neoplastic hepatocytes. (D) Treatment with EIC $400 \mathrm{mg} / \mathrm{kg}$ on HCC bearing animals showing normal architecture with very few pre-neoplastically transformed cells and hepatocytes maintaining normal architecture.

\section{Discussion}

Medicinal plants and natural products have long been used to prevent and treat several diseases; hence they are sensible candidates for the development of newer drugs. Among the anticancer drugs, most of the lead molecules are derived from natural sources. Different screening strategies are available to study the anticancer and chemopreventive efficacy of the test drugs. The current study showed that the oral administration of EIC prevents the hepatocarcinogenesis and development of cancer that is elicited by DEN and PB in experimental rats. It is widely accepted that metabolic activation of DEN by cytochrome P450 enzyme to reactive electrophiles is needed for their cytotoxic, mutagenic and carcinogenic activity. Due to its comparatively easy metabolic pathway and potent carcinogenic activity, DEN has found widespread use as an experimental model in the field of carcinogenesis and in chemoprevention (Borbath et al., 2010).

In the current investigation, the effect of ethanolic extract of I. cordifolia in body weight changes in HCC was carried and showed a significant result in treatment. Liver cancer could cause complex metabolic disturbances in both human and experimental animals leading to loss of 
weight and tissue wasting. There is a considerable loss in body weight in HCC bearing animals as compared to control rats and the reduction in body weight (Glory and Thiruvengadam, 2012). The body weights steadily increased after treatment with extract that indicates that the extract reduces the neoplasm burden and changes in energy metabolism and additionally shows anticarcinogenic efficiency. Relative liver weight is a crucial parameter in judging the pathological conditions of the liver. Relative liver weight was considerably raised in DEN-treated animals because of the increase in liver weight while not increase in weight of the tumour bearing animals treated with the plant extract. The increase in relative liver weight might be because of the liver damage by DEN (Roy and Gadad, 2016). The administration of EIC attenuated the liver weight and relative liver weight that shows the rehabilitating capability of extract in respect with chemopreventive efficiency. Our results are in rational agreement with the previous report (Ghosh et al., 2012).

Biochemical liver marker enzymes are used to screen particularly tumour conditions for differential diagnosis, prognosis, monitoring the progress and for assessing the response to therapy. These enzymes are more unique and changes in their activities reflect the effect of the proliferation of cells with growth potential and its metabolic turnover. The increase in their activities is shown to be in reasonable correlation with the number of transformed cells in cancer conditions. These enzymes serve as an index of liver cell injury and might be used to determine or confirms liver diseases. The comparatively similar elevations of the liver-specific enzymes are considered because of the most sensitive markers in the diagnosis of hepatocellular damage and loss of functional integrity of the cell membrane. The carcinogenesis process in the liver additionally affecting the liver cells with a subsequent breakdown in membrane architecture of the cells ends up in their release into serum wherever their levels goes high (Ramakrishnan et al., 2007). In the present investigation, animals treated with DEN + PB causes hepatocellular damage that was observed from a significant increase in the serum liver marker enzymes like AST, ALT, ALP and GGTP. This kind of elevations was additionally observed by many research groups (Glory and Thiruvengadam, 2012; Roy and Gadad, 2016). The raised levels of those markers are considerably reduced to near normal in HCC bearing animals treated with plant extract that show the anticarcinogenic activity of the extract. The elevated levels of lipids in tumor-bearing animals may be due to decreased activities of lipid metabolising enzymes. This predicts the defective catabolism rather than an elevated synthesis of lipoprotein that appears to be the cause. The total bilirubin level is a biomarker for liver injury. The accumulation of bilirubin in the serum may be a result of decreased biliary excretion when the conjugation of bilirubin in the liver rather than the results of an increased bilirubin load caused by haemolysis. In hepatic tumours, haemolysis and the deranged liver function end up in hyperbilirubinemia. In the present investigation, the HCC bearing animals showed an elevation in levels of serum bilirubin which can be due to the leak of the plasma membrane and loss of functional integrity of cell membranes in liver (Sivaramakrishnan et al., 2008; Chen et al., 2012). The groups treated with EIC showed significant results, reducing the elevated level that indicates the restoration of bilirubin level as well as total cholesterol level.

$\mathrm{DEN}+\mathrm{PB}$ treatment increase the degree of lipid peroxidation in carcinogenic process is also attributable to abnormal levels of reactive oxygen species (ROS) that react with membrane lipids. Measurement of tissue malondialdehyde (MDA), one of the end products of lipid peroxidation, is often used as an indirect index for assessing the extent of lipid peroxidation in tissues (Pracheta et al., 2011). The treatment with EIC down regulates the malonaldehyde (MDA) levels as compared with HCC bearing animals. Thus it is convenient to suggest that the extract positively has a beneficial impact on DEN + PB induced HCC. The presence of 
flavonoids could contribute this effect because they are established to be potent inhibitors of conjugated dienes and are ready to inhibit lipid peroxidation. Phenobarbital is a tumour promoter and it is a powerful inhibitory effect on cellular antioxidant defence systems like SOD, CAT, GST and GPx (Yadav and Bhatnagar, 2007). SOD accelerates the transformation of superoxide anions to hydrogen peroxide, whereas catalase or GPx converts hydrogen peroxide to water. A sharp fall in these antioxidant enzymes will be attributable to increased free radicals production throughout the metabolism of DEN and phenobarbital. Upon treatment with EIC, a rise in the levels of antioxidant enzymes was observed. Additionally, our earlier research on this plant found that it acts as a potent free radical scavenging, antioxidant enzyme-inducing and having anticancer properties (Thangavel et al., 2014; Thangavel et al., 2015). The plant extract additionally contains rich amount of flavonoids, phenolics, ascorbic acid and tannins which could modulate the oxidative status via free radical scavenging and antioxidant enhancing activities in rat liver.

The most commonly used tumour markers for the diagnosis of hepatoma (HCC) is alpha-fetoprotein (AFP) that could be a distinctive immunomodulatory glycoprotein, which is generally made by the immature hepatocytes in the fetus. Approximately in $70 \%$ of the patients with primary HCC, the serum AFP level could also be markedly elevated. It has been recognised that exposure of animals with DEN increases the circulating AFP levels. In our study, the results showing a significant rise in levels of AFP in tumour bearing animals which were found to be reduced in extract treated animals and our results are more consistent with the previous studies (Sivaramakrishnan et al., 2008; Singh et al., 2009; Taha et al., 2010; El Miniawy et al., 2014). Carcinoembryonic antigen (CEA) is an oncofetal glycoprotein that is expressed in normal mucosal cells and is over-expressed in liver and colon cancers. It is frequently detected in high concentrations in the serum of people with liver tumours. It is clear that the CEA assay could be a higher indicator of liver cancer. In the present study, a significant increase in serum CEA levels following DEN treatment was associated with a production rate of tumours, their location, stage, size, vascularity and differentiation. Reduction in CEA expression in extract treated groups indicates the attenuated proliferation rate of liver tumours. Our findings are in good agreement with earlier reports (Ramakrishnan et al., 2007; Jagan et al., 2008).

Nucleic acids play an important role during neoplastic transformation. The determination of nucleic acid content was more important with regards to biological and functional aspects of the tumour. Nucleic acid content is an index of proliferative activity in tumour conditions. Additionally, their content is found to be an independent factor of prognosis since the size of the tumour often correlates with the nucleic acid content of tumour. Deoxyribonucleic acid (DNA) and ribonucleic acid (RNA) synthesis were studied in order to determine the effects of EIC on nucleic acid synthesis in HCC. It has been observed that the tumour growth corresponds to the elevated levels of DNA and RNA synthesis. The level of DNA and RNA of liver found to be progressively increased in HCC bearing animals. The increased nucleic acid synthesis in tumour bearing animals was found to decrease when the animals were treated with EIC. In the present investigation, it has also been observed that decreased protein contents in plasma of HCC bearing animals appear which could be attributed to the impaired hepatic function resulting from infiltration with the tumour. The liver is an important site of protein synthesis and it has the highest rate of synthesis of tissue proteins. Recycling of amino acids has been decreased in tumour conditions resulting in the enhanced efflux of these amino acids from the tissues. Thus, the host responds to increased tumour load by increasing tissue protein breakdown. The administration of EIC to the HCC bearing group resumed the protein level to near normal. 
$\mathrm{DEN}+\mathrm{PB}$ treatment induced histologic changes in the liver like fatty infiltration, focal necrosis and hepatocytes having hyperchromatic nuclei and these changes are indicative of carcinoma. Further, histopathological studies showed the normal architecture, mild congested sinusoids and absence of hepatoma cells in the livers of animals treated with the extract and DEN compared to those treated with DEN alone. All these results indicate that EIC has a chemopreventive impact against the DEN-induced liver tumour.

Our previous studies on this plant have been revealed that the plant extract was rich on several phytochemical compounds like sterols, tannins, phenolics, flavonoids, alkaloids, terpenoids and saponins. Several such compounds are bestknown to possess potent antitumor properties (Kintzios, 2006). The plant extract additionally exerts good radical scavenging and antioxidant activities in numerous in vitro models (Thangavel et al., 2014). The extract has potent antitumour activity in animal models and it enhances the antioxidant enzyme system in tumour bearing animals (Thangave et al., 2015). Flavonoids are known to possess antimutagenic and antitumour effect. In addition to antitumour activity, flavonoids exert growth inhibitory effects on many malignant tumour cell lines in vitro. Moreover, flavonoids have a chemopreventive role in cancer through signal transduction in cell proliferation and development of newer blood vessels (Weber et al., 1996; Fotsis et al., 1997). Flavonoids could inhibit carcinogenesis by inhibiting the metabolic activation of the carcinogen to its reactive intermediate, causing the enzymes involved in the detoxification of the carcinogen and binding to reactive forms of carcinogens, thereby preventing their interaction with vital cellular targets like DNA, RNA and proteins. In addition, plant flavonoids might conjointly inhibit tumour promotional events as mentioned above. It is probably that flavonoids could emerge as a definite group of antitumour agents. Saponins are found beneficial targeted on inhibition of tumour angiogenesis by suppressing its inducer in the epithelial cells of blood vessels then on adhering, invasion and metastasis of tumour cells. They additionally exhibit the antitumour effect by cell cycle arrest and programmed cell death (Man et al., 2010). An antitumour and chemopreventive effect of the extract is also because of the presence of those phytochemical constituents. Hence, the chemopreventive potential of ethanolic extract of $I$. cordifolia is also due to its antioxidant, free radical scavenging and amelioration of lipid peroxidation together with the elevation of antioxidant defence system.

\section{Conclusion}

In conclusion, exposure with DEN clearly evoked liver tumour formation. EIC treatment ameliorated the level of hepatic injury in DEN-treated animals. Our findings suggested that EIC was effective in the treatment of chemically induced liver tumours in rats. The antitumour and chemopreventive mechanisms that concerned in the inhibition of HCC contained the down-regulation of free radicals via antioxidant defence mechanism as well as suppression of inflammatory mediators concerned in carcinogenesis. These findings were of great importance for the invention and development of new and safe medicine for the treatment of liver cancer. Additional studies are warranted to grasp the in-depth mechanism of action which can result in the identification of active molecules from $I$. cordifolia against DEN and PB induced hepatocarcinoma.

\section{Conflict of interest statement}

We declare that there are no conflicts of interest.

\section{References}

Borbath, I.; Leclercq, I. A.; Sempoux, C.; Abarca-Quinones, J.; Desaeger, C.; Horsmans, Y. Efficacy of lanreotide in preventing the occurrence of chemically induced hepatocellular carcinoma in rats. Chem. Biol. Interact., v. 183, p. 238-248, 2010. 
Burton, K. A study of the conditions and mechanism of the diphenylamine reaction for the colorimetric estimation of deoxyribonucleic acid. Biochem. J., v. 62, p. 315-323, 1956.

Chen, B.; Ning, M.; Yang, G. Effect of paeonol on antioxidant and immune regulatory activity in hepatocellular carcinoma rats. Molecules, v. 17, p. 4672-4683, 2012.

Devasagayam, T. P.; Tarachand, U. Decreased lipid peroxidation in the rat kidney during gestation. Biochem. Biophys. Res. Commun., v. 145, p. 134-138, 1987.

El Miniawy, H. M. F.; Ahmed, K. A.; Tony, M. A.; Mansour, S. A.; Khattab, M. M. S. Camel milk inhibits murine hepatic carcinogenesis, initiated by diethylnitrosamine and promoted by phenobarbitone. Int. J. Vet. Sci. Med., v. 2, p. 136-141, 2014.

El-Serag, H. B.; Rudolph, K. L. Hepatocellular carcinoma: epidemiology and molecular carcinogenesis. Gastroenterology, v. 132, p. 2557-2576, 2007.

Fotsis, T.; Pepper, M. S.; Aktas, E.; Breit, S.; Rasku, S.; Adlercreutz, H.; Wahala, K.; Montesano, R.; Schweigerer, L. Flavonoids, dietary-derived inhibitors of cell proliferation and in vitro angiogenesis. Cancer Res., v. 57, p. 2916-2921, 1997.

Ghosh, D.; Choudhury, S. T.; Ghosh, S.; Mandal, A. K.; Sarkar, S.; Ghosh, A.; Saha, K. D.; Das, N. Nanocapsulated curcumin: oral chemopreventive formulation against diethylnitrosamine induced hepatocellular carcinoma in rat. Chem. Biol. Interact., v. 195, p. 206-214, 2012.

Glory, D. M.; Thiruvengadam, D. Potential chemopreventive role chrysin against nnitrosdiethylamine induced hepatocellular carcinoma in rats. Biomed. Prev. Nutr., v. 2, p. 106-112, 2012.

Habig, W. H.; Pabst, M. J.; Jakoby, W. B. Glutathione S-transferases. The first enzymatic step in mercapturic acid formation. J. Biol. Chem., v. 249, p. 7130-7139, 1974.

Jagadeesh, M. C.; Sreepriya, M.; Bali, G.; Manjulakumari, D. Biochemical studies on the effect of curcumin and embelin during $\mathrm{N}$ nitrosodiethylamine/phenobarbital inducedhepatocarcinogenesis in wistar rats. Afr. J. Biotechnol., v. 8, p. 4618-4622, 2009.

Jagan, S.; Ramakrishnan, G.; Anandakumar, P.; Kamaraj, S.; Devaki, T. Antiproliferative potential of gallic acid against diethylnitrosamine-induced rat hepatocellular carcinoma. Mol. Cell. Biochem., v. 319, p. 51-59, 2008.

Jemal, A.; Bray, F.; Center, M. M.; Ferlay, J.; Ward, E.; Forman, D. Global cancer statistics. CA. Cancer J. Clin., v. 61, p. 69-90, 2011.

Khatri, D. K.; Juvekar, P.; Juvekar, A. R. Phytochemical investigation and in vitro antioxidant activities Indigofera cordifolia seed extracts. Intl. J. Pharm. Pharm Sci., v. 5, p. 71-75, 2013.

Kintzios, S. E. Terrestrial plant-derived anticancer agents and plant species used in anticancer research. Crit. Rev. Plant Sci., v. 25, p. 79-113, 2006.

Kumar, V.; Kato, N.; Urabe, Y.; Takahashi, A.; Muroyama, R.; Hosono, N.; Otsuka, M.; Tateishi, R.; Omata, M.; Nakagawa, H.; Koike, K.; Kamatani, N.; Kubo, M.; Nakamura, Y.; Matsuda, K. Genome-wide association study identifies a susceptibility locus for HCVinduced hepatocellular carcinoma. Nat. Genet., p. 43, p. 455-458, 2011.

Lowry, O. H.; Rosebrough, N. J.; Farr, A. L.; Randall, R. Protein measurement with the Folin phenol reagent. J. Biol. Chem., v. 193, p. 265-275, 1951.

Man, S.; Gao, W.; Zhang, Y.; Huang, L.; Liu, C. Chemical study and medical application of saponins as anti-cancer agents. Fitoterapia, v. 81, p. 703-714, 2010.

Mandal, A.; Das, S.; Mitra, M.; Chakrabarti, R. N.; Chatterjee, M.; Das, N. Vesicular flavonoid in combating diethylnitrosamine induced hepatocarcinoma in rat model. J. Exp. Ther. Oncol., v. 7, p. 123-133, 2008.

Marklund, S.; Marklund, G. Involvement of the superoxide anion radical in the autoxidation of pyrogallol and a convenient assay for superoxide dismutase. Eur. J. Biochem., v. 47, p. 469-474, 1974.

Pracheta, P.; Sharma, V.; Singh, L.; Paliwal, R.; Sharma, S.; Yadav, S.; Sharma, S. Chemopreventive effect of hydroethanolic extract of Euphorbia neriifolia leaves against DENA-induced renal carcinogenesis in mice. Asian Pac. J. Cancer Prev., v. 12, p. 677-683, 2011.

Rajkapoor, B.; Murugesh, N.; Chodon, D.; Sakthisekaran, D. Chemoprevention of Nnitrosodiethylamine induced phenobarbitol promoted liver tumors in rat by extract of Indigofera aspalathoides. Biol. Pharm. Bull., v. 28, p. 364-366, 2005. 
Ramakrishnan, G.; Augustine, T. A.; Jagan, S.; Vinodhkumar, R.; Devaki, T. Effect of silymarin on $\mathrm{N}$-nitrosodiethylamine induced hepatocarcinogenesis in rats. Exp. Oncol., v. 29, p. 39-44, 2007.

Rotruck, J.; Pope, A. L.; Ganther, H. E.; Swanson, A. B.; Hafeman, D. G.; Hoekstra, W. G. Selenium: biochemical role as a component of glutathione peroxidase. Science, v. 179, p. 588-590.

Roy, S. R.; Gadad, P. C. Effect of $\beta$-asarone on diethylnitrosamine-induced hepatocellular carcinoma in rats. Indian J. Health Sci., v. 9, p. 82-88, 2016.

Sarin, R.; Upman, S. Extraction of sterols from in vivo and in vitro tissue cultures of Indigofera cordifolia and I. linnaei. Intl. J. Adv. Pharm. Res., v. 2, p.122-126, 2011.

Schinder, W. C. Determination of nucleic acid in tissue by pentose analysis. In: Colowick, S. P.; Kaplon, N. O. (Eds.). Methods in enzymology. New York: Academic Press, 1957. v. 3. p. 680-684.

Shih, W. L.; Yu, M. W.; Chen, P. J.; Wu, T. W.; Lin, C. L.; Liu, C. J.; Lin, S. M.; Tai, D. I.; Lee, S. D.; Liaw, Y. F. Evidence for association with hepatocellular carcinoma at the PAPSS1 locus on chromosome 4 q25 in a family-based study. Eur. J. Hum. Genet., v. 17, p. 1250-1259, 2009.

Singh, B. N.; Singh, B. R.; Sharma, B. K.; Singh, H. B. Potential chemoprevention of N-nitrosodiethylamine-induced hepatocarcinogenesis by polyphenolics from Acacia nilotica bark. Chem. Biol. Interact., v. 181, p. 20-28, 2009.

Sinha, A. K. Colorimetric assay of catalase. Anal. Biochem., v. 47, p. 389-394, 1972.
Sivaramakrishnan, V.; Shilpa, P. N.; Praveen Kumar, V. R.; Niranjali Devaraj, S. Attenuation of N-nitrosodiethylamine-induced hepatocellular carcinogenesis by a novel flavonolMorin. Chem. Biol. Interact., v. 171, p. 79-88, 2008.

Taha, M. M.; Abdul, A. B.; Abdullah, R.; Ibrahim, T. A.; Abdelwahab, S. I.; Mohan, S. Potential chemoprevention of diethylnitrosamine-initiated and 2-acetylaminofluorenepromoted hepatocarcinogenesis by zerumbone from the rhizomes of the subtropical ginger (Zingiber zerumbet). Chem. Biol. Interact., v. 186, p. 295-305, 2010. https://dx.doi.org/10.1016/j.cbi.2010.04.029

Tambe, A. D.; Chaudhari, T. B.; Chaudhari, R. S. Wound healing activity of Indigofera cordifolia aerial part extracts in rats. J. Pharm. Res., v. 3, p. 1417-1419, 2010.

Thangavel, D.; Govindasamy, J.; Kumar, R. S. Anticancer and antioxidant activities of ethanol extract of Indigofera cordifolia Roth. on Ehrlich Ascites Carcinoma tumour bearing mice. Intl. J. Phytother., v. 5, p. 111-117, 2015.

Thangavel, D.; Govindasamy, J.; Kumar, R. S. In vitro antioxidant and anticancer activities of various extracts of Indigofera cordifolia Roth. J. Pharm. Biol., v. 4, p. 85-93, 2014.

Weber, G.; Shen, F.; Prajda, N.; Yeh, Y. A.; Yang, H.; Herenyiova, M.; Look, K. Y. Increased signal transduction activity and downregulation in human cancer cells. Anticancer Res., v. 16, p. 271-3282, 1996.

Yadav, A. S.; Bhatnagar, D. Chemo-preventive effect of Star anise in N-nitrosodiethylamine initiated and phenobarbital promoted hepatocarcinogenesis. Chem. Biol. Interact., v. 169, p. 207-214, 2007. 